\title{
LASSCI2009.2: layered earthquake rupture forecast model for central Italy, submitted to the CSEP project
}

\author{
Bruno Pace $^{1,{ }^{\star}}$, Laura Peruzza $^{2}$, Francesco Visini $^{1}$ \\ ${ }^{1}$ GEOSISLAB - Università degli Studi "G. D'Annunzio", Chieti Scalo, Italy \\ ${ }^{2}$ OGS - Istituto Nazionale di Oceanografia e Geofisica Sperimentale, Sgonico (Trieste), Italy
}

\author{
Article history \\ Received November 8, 2009; accepted August 24, 2010. \\ Subject classification: \\ Earthquake rupture forecast, Central Italy, Model validation, Time-dependent seismic hazard assessment.
}

\section{ABSTRACT}

The Collaboratory for the Study of Earthquake Predictability (CSEP) selected Italy as a testing region for probabilistic earthquake forecast models in October, 2008. The model we have submitted for the two medium-term forecast periods of 5 and 10 years (from 2009) is a time-dependent, geologically based, earthquake rupture forecast that is defined for central Italy only $\left(11-15^{\circ} \mathrm{E} ; 41-45^{\circ} \mathrm{N}\right)$. The model took into account three separate layers of seismogenic sources: background seismicity; seismotectonic provinces; and individual faults that can produce major earthquakes (seismogenic boxes). For CSEP testing purposes, the background seismicity layer covered a range of magnitudes from 5.0 to 5.3 and the seismicity rates were obtained by truncated Gutenberg-Richter relationships for cells centered on the CSEP grid. Then the seismotectonic provinces layer returned the expected rates of medium-to-large earthquakes following a traditional Cornell-type approach. Finally, for the seismogenic boxes layer, the rates were based on the geometry and kinematics of the faults that different earthquake recurrence models have been assigned to, ranging from pure GutenbergRichter behavior to characteristic events, with the intermediate behavior named as the hybrid model. The results for different magnitude ranges highlight the contribution of each of the three layers to the total computation. The expected rates for $M>6.0$ on April 1, 2009 (thus computed before the L'Aquila, 2009, $M_{\mathrm{w}}=6.3$ earthquake) are of particular interest. They showed local maxima in the two seismogenic-box sources of Paganica and Sulmona, one of which was activated by the L'Aquila earthquake of April 6, 2009. Earthquake rates as of August 1, 2009, (now under test) also showed a maximum close to the Sulmona source for $M_{\mathrm{w}} \sim 6.5$; significant seismicity rates (10-4 to 10-3 in 5 years) for destructive events (magnitude up to 7.0) were located in other individual sources identified as being capable of such earthquakes in the central part of this area of the Apennines.

\section{Introduction}

In the framework of the seismic hazard validation activities planned by the Collaboratory for the Study of Earthquake Predictability (CSEP) [Schorlemmer et al. 2006, Schorlemmer et al. 2009], we implemented a layered seismogenic source model in central Italy (LASSCI) [Pace et al. 2006, Peruzza et al. 2007], to submit two medium-term forecasts to formal statistical tests on the observed seismicity rates over the periods of 2009-2014 and 2009-2019.

The model was issued as a first release (LASSCI2009.1) after a workshop held in Rome, Italy (October 2008; http: / / www.cseptesting.org/meetings/rome20081027), and it was ready to be submitted for an initial deadline set for April 1, 2009. The occurrence of a major earthquake on one of the sources we had considered as a time-dependent characteristic event source (hereinafter described as the 12Paganica source) required further revision. This has led to a second release, in which the time elapsed since the last event for the Paganica source dropped from 548 years to zero. This release (LASSCI2009.2) has been submitted for the ongoing CSEP test. As such, it should be used for retrospective testing only outside the Paganica box.

In the next sections, we describe the original seismogenic source model and the implementations made in the model in preparation for submission to the CSEP experiment.

\section{The layered seismogenic source model for central Italy}

The LASSCI is an earthquake rupture forecast model that was developed in the early 2000s, and it is based on a full analysis of geological, structural and seismological data. Initially published in 2006 [Pace et al. 2006, Peruzza et al. 2007], the LASSCI defined different kinds of seismogenic sources, and in some locations the details reached addressed individual active faults [Barchi et al. 2000, Galadini and Galli 2000, Galadini et al. 2000, Boncio et al. 2004]. The sources were formally combined together (layered) into a probabilistic seismic hazard assessment, under stationary and time-dependent perspectives.

The LASSCI is based on three separate layers of seismogenic sources: the seismotectonic provinces (SPs), individual faults that are capable of major earthquakes 

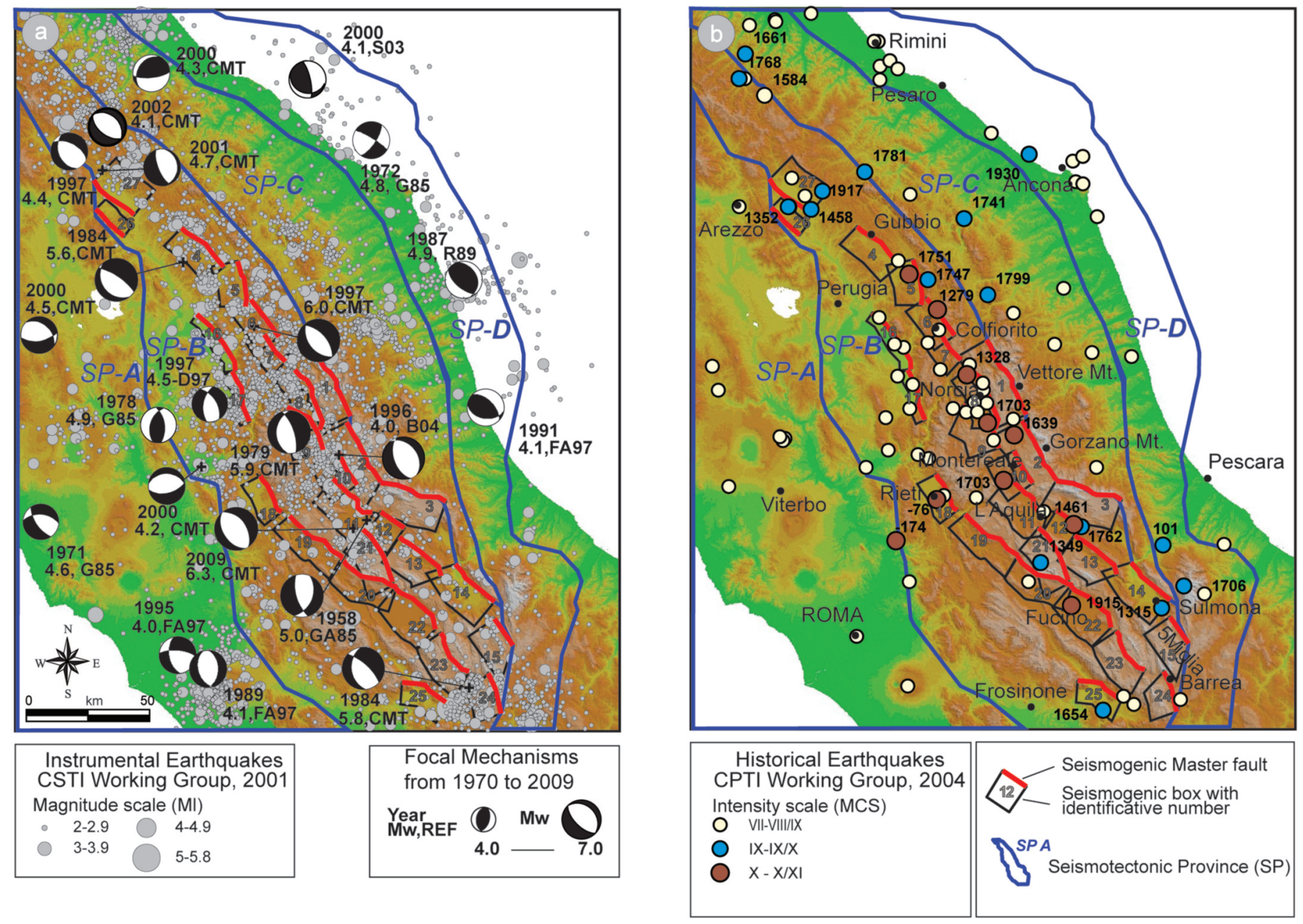

Figure 1. Layered seismogenic source model in central Italy. (a) Map of the SP and SB sources, of instrumental seismicity (CSTI) [CSTI Working Group 2001] and focal mechanisms of the main events; the source codes are as follows: G85, Gasperini et al. [1985], R89, Riguzzi et al. [1989], FA97, Frepoli and Amato [1997], D97, Di Luccio et al. [1997], S03, Santini [2003], B04, Boncio et al. [2004], CMT, catalog at www.seismology.harvard.edu and MedNet regional at www.mednet.ingv.it. The geometries were the same as those of Pace et al. [2006], except for the SBs near Arezzo (Città di Castello sources) [Brozzetti et al. 2009]; (b) Map of the SP and SB sources, and of historical seismicity (CPTI) [CPTI Working Group 2004].

(seismogenic boxes, SBs) and background sources (BKs). These are described in detail below.

\section{Seismotectonic Provinces}

The SPs are large structural domains for which the boundaries are mainly defined by taking into account the three-dimensional geometry of major active structural elements, together with seismological data like earthquake focal mechanisms, rheological and geodetic data. Each SP was considered homogeneous in terms of the active tectonics. From the Tyrrhenian coast to the Adriatic coast, four SPs were identified (Figure 1a, thick blue lines): SP-A is the Tuscan-Latium domain, with a thinned crust, high heatflow values, and minor shallow seismicity; SP-B represents the axial belt of the Apennine extensional domain, where most historical and instrumental strong earthquakes have been located, and where normal active faults are mapped; SP-C corresponds to the foothill regions, where mixed kinematics have been detected; and finally, SP-D is the coastal strip of the Adriatic that is dominated by buried thrusts, folds and strike-slip faults, and where past earthquakes have never exceeded M 5.0. For all of these SPs, except SP-B, the expected rates of medium-to-large earthquakes were calculated by simply extracting the earthquakes located inside the SPs. This kind of source follows the traditional Cornell-type approach of assuming a homogeneous distribution of earthquakes in space, a Gutenberg-Richter (G-R) magnitude relationship, and a stationary process of earthquakes in time. The «learning» datasets were the historical CPTI catalog [CPTI Working Group 2004], which contained earthquakes from the 2nd century B.C. to 2002, and the instrumental CSTI catalog [CSTI Working Group 2001], which covered 15 years from 1981. The completeness of the CPTI database covered the past 400 years for $M<6.4$, and 1,000 years for $M \geq 6.4$, while the magnitude of completeness for the CPTI catalog was set to $M$ 5.5. The instrumental database was considered complete above $M 2.0$ for the period the CSTI refers to (i.e., 1981 onwards). The two databases overlapped in time for $M>4.0$, and additional details of declustering are given in the background paragraph (below) and were in the original publication [Pace et al. 2006]. 


\section{Seismogenic Boxes}

Inside the extensional Apennine province SP-B, major active seismogenic faults have been identified, which were considered continuous at depth for several kilometers and capable of resulting in large earthquakes $(M \geq 5.5)$. A SB is the plan projection of the three-dimensional geometry of such master faults, which is constrained by structuralgeological, morphotectonic, paleoseismological and rheological data. The geometry, kinematics and observed seismicity controlled the maximum expected magnitude $\left(M_{\max }\right)$ for each of the 28 SBs parameterized in 2006 inside SPB. The mean recurrence time $\left(T_{\text {Mmax }}\right)$ was also inferred indirectly, as repeated earthquakes were available only from paleoseismological analyses of a few faults [see Pace et al. 2006: tables 2, 3 and figs. 4, 5]. Each SB was characterized by its own earthquake recurrence model: a pure logarithmic frequency-magnitude (G-R behavior) was assigned to a source if its seismological records covered a wide continuous range of magnitudes ( 5 SBs); alternatively, a Gaussian peak centered on the maximum magnitude allowed by the fault dimension (characteristic earthquake model; $\mathrm{CH}$ model) was assigned to SBs that had experienced only a major earthquake, or that have been silent during historical and instrumental times (14 SBs). Intermediate behavior, named as the hybrid (HY) model, was allocated to the remaining nine SBs for which the observed earthquakes suggested a characteristic peak, and a separate G-R distribution at low magnitudes. It is worth noting that Californian fault hazard modelers [e.g. Jordan et al. 2006, WGCEP 2008] adopted the same earthquake recurrence models, with their Type $\mathrm{C}$ source corresponding to our G-R behavior, Type A to our CH model, and Type B to our HY model. In contrast to the approach in the U.S.A., the Italian faults were not classified on the basis of the degree of knowledge (none of the mapped Italian sources satisfies the rules of a Type A fault), but mainly on the basis of their earthquake-fault association over the last millennium. The expected earthquake rates were therefore assigned to each $\mathrm{SB}$, anchoring the frequency-magnitude distributions on the values of $M_{\max }$ and $1 / T_{M \max }$. A fixed $b$-value of 1.0 (obtained using all of the earthquakes that have occurred in the Apennine extensional SP-B) was given to the G-R sources, and the Gaussian distribution was truncated at a standard deviation $\sigma_{M}$ of 0.3 . These "geologically driven" earthquake models can alone explain all of the observed seismicity in SP-B, which overlapped the historical rates in some magnitude ranges: this was consistent with the modeling of earthquake occurrences that were not represented in the catalog.

Finally, if a fault was modeled with characteristic earthquake behavior, the time-dependency was introduced by a renewal process, which considered the elapsed time from the occurrence of the last event. By adopting the formulation of the BPT distribution [Matthews et al. 2002], the probability of having a characteristic earthquake of a given magnitude conditional on the elapsed time in a given $t$ years should be expressed as an equivalent Poissonian fictitious return time $T_{\text {fictitious }}$, as given by Equation (1):

$$
T_{\text {fictitious }}=\frac{-t}{\ln (1-P(\text { Char_event } \mid \text { telapsed }))}
$$

from which the time-dependent seismic hazard maps were computed [Pace et al. 2006: fig. 13].

\section{Background Sources}

Cells of dimensions $0.1^{\circ} \times 0.1^{\circ}$ (latitude $\times$ longitude) covered the whole of the study area in a nearly continuous pattern, and they represented the diffuse background low to medium seismicity $(M<5.5)$. The CSTI instrumental catalog [CSTI Working Group 2001] that covered the period from 1981 to 1996 was used in the data gathering and magnitude assessment for homogeneity reasons. The CSTI catalog was declustered using a downward interpolation of the Knopoff [2000] table to satisfy stationarity; deep events (h > $50 \mathrm{~km})$ and earthquakes below completeness magnitudes $(M<2.0)$ were removed. From an original set of about 34,700 earthquakes, this procedure yielded a subset of 15,364 events, of which about $1 / 3$ were located in the study area. An electronic version of the filtered catalog is available from the authors on request. The expected seismicity rates were obtained by truncated G-R relationships, using a regularly spaced spatial grid $\left(0.1^{\circ} \times 0.1^{\circ}\right)$ and a search radius of $20 \mathrm{~km}$ from the center of each cell. The G-R $a$ and $b$ parameters were computed only on subsets of more than five earthquakes, using a least-squares method. Sensitivity analyses have demonstrated that these choices (spatial kernel, fitting algorithm, and the use of small data samples) have a negligible impact on seismic hazard maps. The G-R coefficients were applied in the magnitude range from 3.0 to 5.5 for all of the BK sources, except those located inside one of the SPs (SP-B), for which the upper limit was decreased $(M=4.5)$ due to a more detailed characterization of individual SBs.

We describe in the next section how the original LASSCI parameters were modified to satisfy the requirements of the CSEP experiment, along with the improvements in the fault parameterization that have been made over the last few years.

\section{From 2006 to 2009: the CSEP improvements}

When Italy was selected as the testing region for this CSEP experiment, we decided to submit the LASSCI because the basic assumptions and data that were available were, in our opinion, still up-to-date. We kept the LASSCI as close as possible to the 2006 published version, and therefore avoided the need to change the instrumental or historical databases, fault geometries, and earthquake-to-fault associations for the SBs; similarly we avoided changing other computational choices that were not adopted now - e.g., choices made in characterizing the BKs (see below) - to preserve the same 


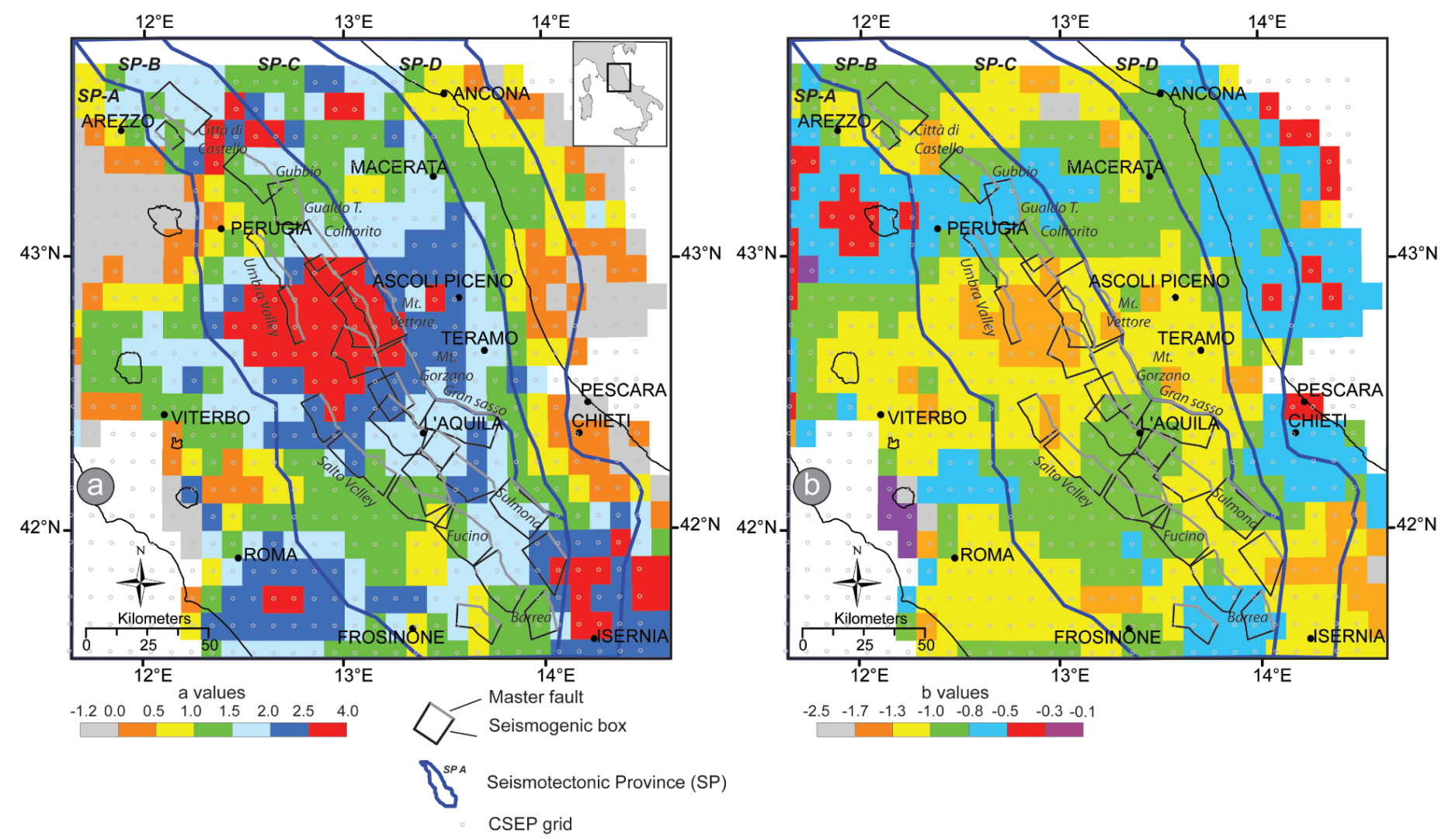

Figure 2. Maps of the Gutenberg-Richter coefficients computed using a grid node spacing of $0.1^{\circ} \times 0.1^{\circ}$ and a search radius of $20 \mathrm{~km}$. The grid has the same spacing as in the original study in Pace et al. [2006], but it was shifted by $0.05^{\circ}$ for the CSEP project. The dataset was the instrumental catalog from 1981 to 1996 (CSTI) [CSTI Working Group 2001]. The catalog was declustered following Knopoff [2000], to satisfy stationarity, and deep events $(\mathrm{h}>50 \mathrm{~km})$ and low magnitudes $(M<2.0)$ were also filtered. The Gutenberg-Richter relationship was determined using the least-squares method. White nodes refer to subsets with too few events $(\mathrm{n} \leq 5)$ to compute the G-R interpolation.

seismic hazard pattern in low seismicity areas. These areas are therefore poorly constrained at present, just as they were some years ago. Instead, the main effort was focused on introducing error treatments of the SB parameters [following recent studies, e.g., Peruzza et al. 2010], and in formatting the LASSCI as requested by the rules of the CSEP project. For the medium-term forecasts, the Italian testing experiments required the expected seismicity rates for two time frames (2009-2014 and 2009-2019; starting date: August $1,2009)$ in the range of magnitudes from 5 to 9 , with a bin of 0.1 , on a predefined spatial grid with $0.1^{\circ}$ spacing (http://www.cseptesting.org/meetings/rome20081027). A short description of the modifications made to each of the three layers follows.

\section{BK-Background}

As previously indicated, we decided to maintain the original choice of earthquake catalogs as we considered them to still be reliable [see comments in Pace et al. 2006]. The BK cells of the 2006 model had the spacing requested by the CSEP project, but did not exactly coincide with the testing grid nodes. We therefore repeated the search within a $20 \mathrm{~km}$ distance of the new points that were shifted by $0.05^{\circ}$ with respect to the original locations, and recomputed the G-R coefficients. In Figure 2, the new $a$ and $b$ values obtained with the least squares method are mapped: only the nodes with at least five events were represented, and the $a$ values were normalized to one year, and to a $10 \times 10 \mathrm{~km}$ unit area. Conversely, the minimum magnitude $(M=5.0)$ required by CSEP meant that we had to modify the original choice of BK upper limit that was set up by Pace et al. [2006] at $M=4.5$ inside SP-B, and at $M=5.5$ inside the other SPs. In 2006, this choice was made to avoid overlaps with the seismicity distribution given for the SBs in SP-B, and to take into account the completeness magnitude threshold of the historical catalog elsewhere. This had been consistent with the aim of the previous study (as a representation of the seismic activity in terms of traditional hazard maps, as peak ground acceleration was not expected to be exceeded at a given probability level in a given time frame), but it was not adequate for the CSEP testing that now required earthquake rates on grid points in magnitude bins of 0.1. By excluding the BKs for $M<5.0$, many nodes outside the SBs would have remained completely aseismic, a choice which we considered as not acceptable. We therefore defined new criteria for the selection of a homogeneous upper magnitude of BKs over the entire study area. The new, spatially homogeneous upper boundary for the BK sources was $M_{\max }=5.3$, which was obtained by minimizing the cumulative misfit of the 
seismic moment rate as given by the experimental data (the catalog content) and theoretical G-R models ( $a$ and $b$ coefficients). In Figure 3, the misfit between the observed and calculated seismic moments is shown for increasing magnitudes from 5.0 to 5.5 , with the G-R coefficients computed by least-squares fitting and maximum-likelihood methods. We noted that: (i) the misfit rapidly increased when the upper limit of the magnitude threshold reached 5.5; and (ii) the use of different fitting methods had minor effects on the misfit, even if the maximum-likelihoodderived coefficients caused systematically higher misfits.

For these reasons, our final choice for the G-R computation of the expected seismicity rates for the BK layer was to determine the least-squares fitting coefficients applied to a range of magnitudes (5.0 - 5.3). We performed other sensitivity analyses on the sample-size threshold used to compute local G-R relationships, and on the fitting method; the $a$ and $b$ coefficients remained unchanged when the interpolation was applied to sample sizes of more than about 30 events, but the effects of poorly constrained cells was not crucial on a seismic hazard map, as it is the highest rates ( $a$ values $>1.5$ eqs $/ \mathrm{yr}$ in Figure 2a) that mainly control the results.

As the «learning» dataset for the BKs was limited to data collected prior to and including 1996, a forecast testing in this magnitude range (5.0 - 5.3) was possible, performed retrospectively starting with data from 1997.

\section{SP-Seismotectonic Provinces}

The SPs were used to model the expected earthquake rates with $M>5.3$ that were not directly correlated to the SBs, and therefore comprised SP-A, SP-C and SP-D: in SP-B, the $\mathrm{SBs}$ alone were sufficient to explain and overcome all of the observed seismicity, and therefore this SP was not modeled as an area of homogeneously distributed seismicity, but rather by SBs and BKs only. As no earthquake with $M>5.3$ had occurred in these three SPs since the end of the catalog (December, 2002), we retained the G-R relationships computed in 2006 [see Pace et al. 2006: fig. 7]. Criticisms of this previous parameterization had arisen from the heterogeneous definition of the magnitude in different earthquake catalogs. In our case, the instrumental catalog (CSTI) [CSTI Working Group 2001] uses local magnitudes $\left(M_{L}\right)$ for the period 1981-1996, while the historical dataset (CPTI04) [CPTI Working Group 2004] gives estimates referred to as moment magnitudes that had been mainly derived by converting the macroseismic intensities into $M_{w}$. We therefore checked these magnitudes by transforming the $M_{\mathrm{L}}$ values of the instrumental catalog in $M_{\mathrm{w}}$ values using the empirical relationship used by MPS Working Group [2004]:

$$
M_{\mathrm{w}}=0.812 M_{\mathrm{L}}+1.145 \text {. }
$$

The G-R distributions obtained from the historical and

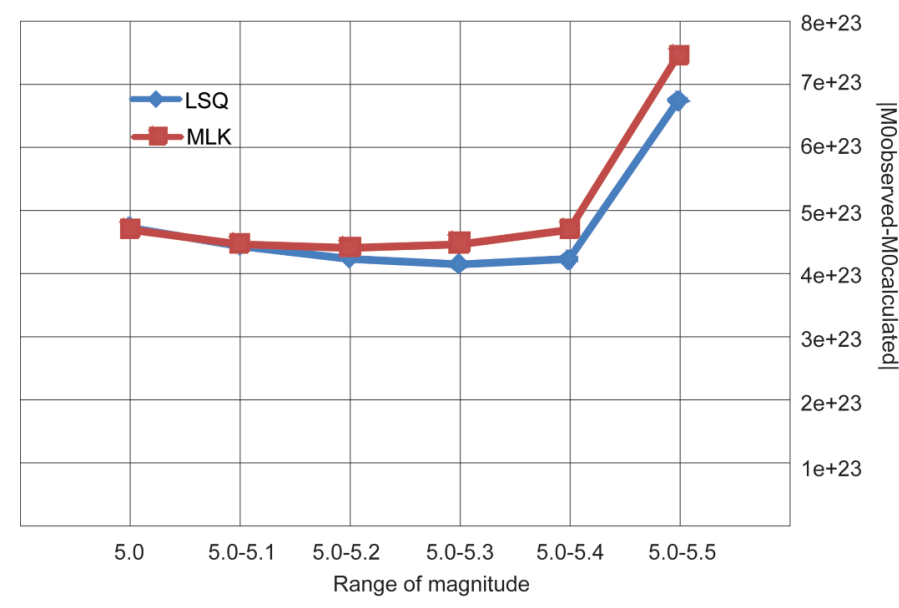

Figure 3. Differences between the observed cumulative moments from the instrumental catalog [CSTI Working Group 2001] and the calculated cumulative moments using G-R relationships with two different interpolation algorithms (LSQ, least square method; MLK, maximum likelihood method); six magnitude intervals are plotted, with increasing upper boundary limit.

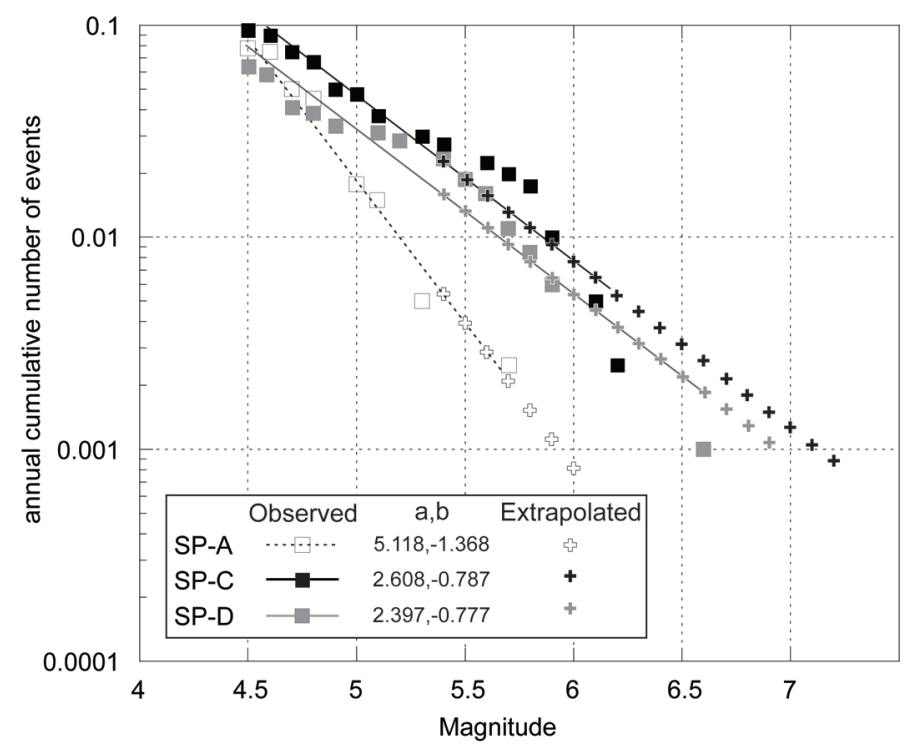

Figure 4. Earthquake rates assigned to the three SPs (SP-A, SP-C and SPD) where the homogeneously distributed seismicity was modeled. The observed rates came from the CPTI04 historical catalog [CPTI Working Group 2004] for $M>5.5$, and from the CSTI instrumental catalog [CSTI Working Group 2001] below. $M_{\mathrm{L}}$ were converted into $M_{\mathrm{w}}$ as explained in the main text. The extrapolated rates (crosses) are the G-R relationships obtained using the least-squares method on magnitude bins of 0.1 , from the lower bound at $M=5.4$ to the upper bound corresponding approximately to 0.001 earthquakes/year inside the whole of the SP.

instrumental datasets overlapped better with the "homogeneous» magnitude, and the G-R relationships derived from the CPTI04 historical catalog in 2006 were considered representative of the expected seismicity rates inside the SPs (Figure 4), even at magnitudes below the completeness threshold of the historical dataset (M 5.5). The lower threshold of the magnitude of the SPs was fixed at 5.4 $\left(M_{\mathrm{w}}\right)$ to avoid the duplication of rates between the BK and SP layers; upward distributions were truncated at magnitudes corresponding to an annual rate of $10^{-3}$.

A problem of heterogeneity in magnitude assessments 


\begin{tabular}{|c|c|c|c|c|c|}
\cline { 2 - 6 } \multicolumn{2}{l|}{} & $\mathbf{n}^{\circ}$ sources & $\mathbf{n}^{\circ}$ nodes & node allocation method & seismicity rates calculation method \\
\hline \multirow{2}{*}{} & $B K$ & 629 & 629 & one to one & $\begin{array}{c}\text { G-R CSTI } \\
\text { magnitude range } 5.0-5.3\end{array}$ \\
\cline { 2 - 6 } & $S P$ & 3 & 368 & area source $/ \mathrm{n}^{\circ}$ nodes & $\begin{array}{c}\text { G-R CPTI } \\
\text { magnitude range } 5.4-M_{\text {max-1000y }}{ }^{\star}\end{array}$ \\
\cline { 2 - 6 } & $S B$ & 27 & 119 & percentage of area coverage & $\begin{array}{c}\text { individual boxes modeling, time-dependency or not } \\
\text { magnitude range } 5.4-\mathrm{M}_{\text {maxind }}^{\star \star}\end{array}$ \\
\hline
\end{tabular}

Table 1. Summary of information for each of the three layers of the LASSCI2009.2. BK, background layer; SP, seismotectonic provinces; SB, seismogenic boxes layer. For each layer, the number of sources is given with the total number of nodes of the CSEP-grid contained in the layer. The column «node allocation method» briefly describes how the total rates for each source were assigned to the nodes of the grid. The last column summaries the main method for the seismicity rate computations and the range of magnitudes covered by the layer ( ${ }^{\star}: M_{\max }$ value corresponding to a mean recurrence time of $\sim 1,000$ years; ${ }^{\star \star}: M_{\max }$ value calculated from the geometry of each individual source; details in Pace et al. 2006).

\begin{tabular}{|c|c|c|c|c|c|}
\hline SEISMOGENIC BOXES (SB) & last maximum observed earthquakes & $\begin{array}{c}\text { expected } \\
M_{\max }\end{array}$ & $\begin{array}{c}\text { expected } \\
T_{M \max }\end{array}$ & model & Tdep \\
\hline 1 Bove-Vettore & 4155/3965 BP-600/ 700 AD (paleo) & 6.9 & 1348 & $\mathrm{CH}$ & yes \\
\hline 2 Gorzano & $1639 / 10 / 07$ (hist) & 6.7 & 1927 & $\mathrm{HY}$ & yes \\
\hline 3 Gran Sasso & after $3480 / 3400$ BP (paleo) & 6.7 & 1110 & $\mathrm{CH}$ & yes \\
\hline 4 Gubbio & $1984 / 04 / 29$ (instr) & 6.4 & 795 & GR & no \\
\hline 5 Gualdo Tadino & $1751 / 07 / 27$ (hist) & 6.4 & 1114 & $\mathrm{HY}$ & yes \\
\hline 6 Colfiorito & $1997 / 09 / 26$ (instr) & 6.4 & 1105 & $\mathrm{CH}$ & yes \\
\hline 7 S. Martino-Civitella & $1997 / 10 / 14$ (instr) & 6.1 & 697 & GR & no \\
\hline 8 Nottoria-Preci & $1703 / 01 / 14$ (hist) & 6.7 & 2007 & $\mathrm{HY}$ & yes \\
\hline 9 Cascia-Cittareale & $1703 / 01 / 14$ (hist) & 6.6 & 1127 & $\mathrm{HY}$ & yes \\
\hline 10 Montereale & $1703 / 01 / 16$ (hist) & 6.4 & 724 & $\mathrm{CH}$ & yes \\
\hline 11 Pizzoli-Pettino & $1703 / 02 / 02$ (hist) & 6.6 & 1319 & $\mathrm{CH}$ & yes \\
\hline 12 Paganica & 2009/04/06 (instr) & 6.3 & 493 & $\mathrm{CH}$ & yes \\
\hline 13 Media Valle Aterno & $>3000 \mathrm{BP}($ paleo $)$ & 6.6 & 2180 & $\mathrm{CH}$ & yes \\
\hline 14 Sulmona & 100 (hist) & 6.6 & 926 & $\mathrm{CH}$ & yes \\
\hline 15 Pizzalto-Cinquemiglia & $1315 / 12 / 03$ (hist) & 6.5 & 1229 & $\mathrm{CH}$ & yes \\
\hline 16 Valle Umbra $N$ & $1832 / 01 / 13$ (hist) & 5.7 & 190 & GR & no \\
\hline 17 Valle Umbra $S$ & $1878 / 09 / 15$ (hist) & 5.7 & 246 & GR & no \\
\hline 18 Rieti & $1898 / 06 / 27$ (hist) & 6.3 & 1214 & $\mathrm{HY}$ & no \\
\hline 19 Valle del Salto & 1 & 6.6 & 1287 & $\mathrm{CH}$ & no \\
\hline 20 Velino-Magnola & 1904/ 02/ 24 (hist) & 6.6 & 920 & $\mathrm{HY}$ & no \\
\hline 21 Campo Felice-Ovindoli & $1349 / 09 / 09$ (hist) & 6.7 & 749 & $\mathrm{CH}$ & yes \\
\hline 22 Fucino & $1915 / 01 / 13$ (instr) & 6.6 & 702 & $\mathrm{CH}$ & yes \\
\hline 23 M. Marsicano & 1 & 6.5 & 991 & $\mathrm{CH}$ & no \\
\hline 24 Barrea & 1984/05/07 (instr) & 6.4 & 1226 & GR & no \\
\hline 25 Sora & $1654 / 07 / 23$ (hist) & 6.4 & 1898 & $\mathrm{HY}$ & no \\
\hline 26 M.S. Maria Tiberina & 1917/04/26 (instr) & 5.9 & 663 & $\mathrm{CH}$ & yes \\
\hline 27 Città di Castello & $1458 / 04 / 26$ (hist) & 6.5 & 1300 & $\mathrm{HY}$ & yes \\
\hline
\end{tabular}

Table 2. Seismogenic boxes parameterization. Last maximum observed earthquakes were taken from: hist, CPTI Working Group [2004]; instr, instrumental catalog CSTI Working Group [2001], and ISIDE database available at http:/ / iside.rm.ingv.it/iside; paleo, paleoseismological data from Galli et al. [2008] and references therein (for 13-Media Valle Aterno, Falcucci et al. 2009). «Expected $M_{\max }$ and "expected $T_{M \max }$ " represent the expected maximum magnitude and mean recurrence time [see details in Peruzza et al. 2010]. The type of model chosen was: $\mathrm{CH}$ bell-shaped approximation of a characteristic earthquake; GR, Gutenberg-Richter exponential distribution function; HY, hybrid model with a characteristic peak and a G-R tail for smaller magnitudes. The final column indicates if a time-dependent approach was used for the SB.

still persists, which was enhanced by the recent L'Aquila earthquake $\left(M_{\mathrm{L}}=5.8 ; M_{\mathrm{w}}=6.3\right)$ [Chiarabba et al. 2009], although this is outside the scope of this report and will have to be handled as necessary by the CSEP validation team.

As the «learning» dataset for each SP was limited to data prior to and including 2002, we believed that the forecast testing for magnitude $M>5.4$ could be retrospectively performed inside SP-A, SP-C and SP-D starting with data collected since 2003.

According to the homogeneous and uniform distributions of seismicity invoked for seismic hazard purposes, the SP earthquake rates were uniformly partitioned on the CSEP grid nodes (see Table 1). 

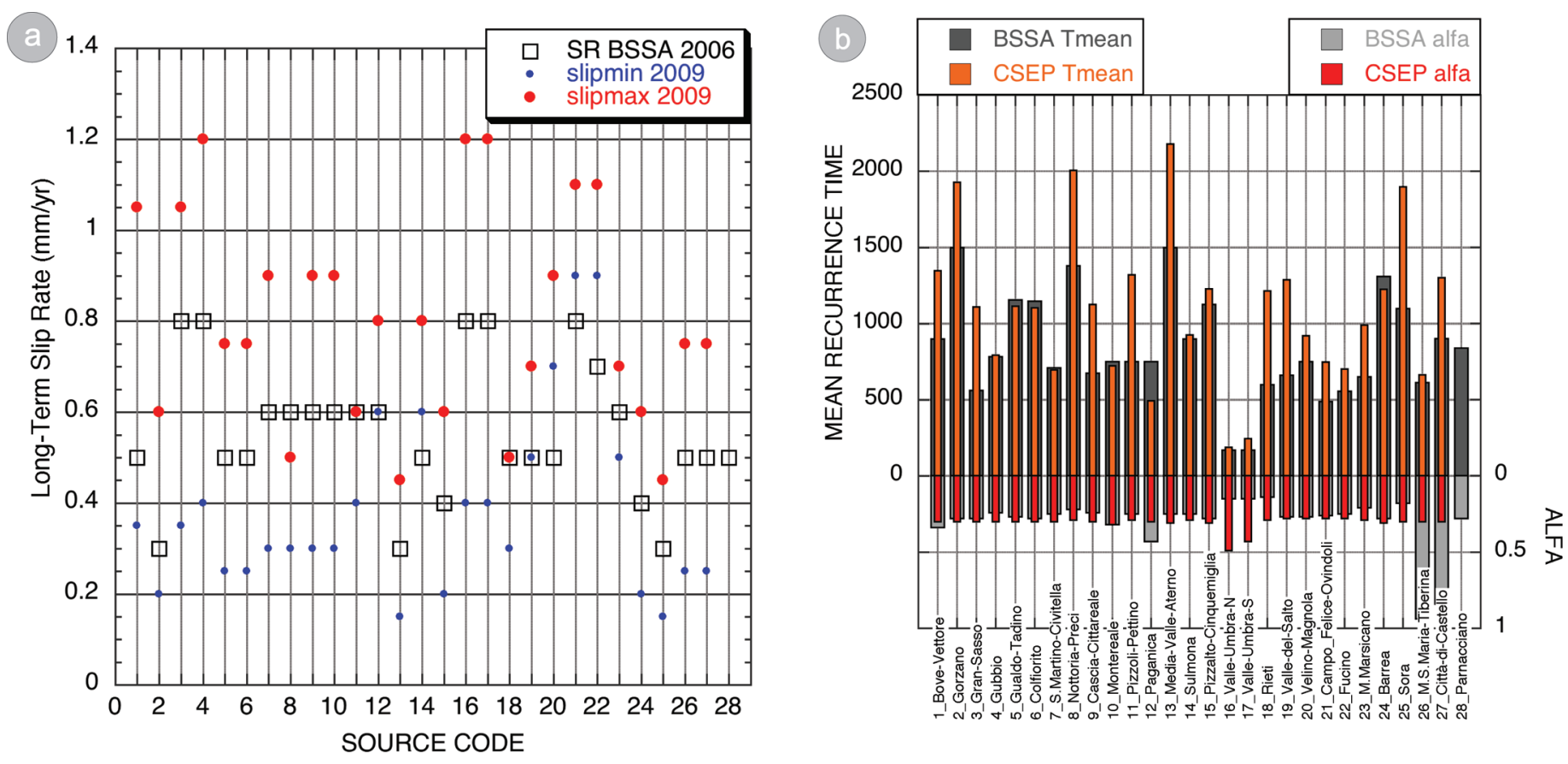

Figure 5. Implementations made to the CSEP test based on the SB sources. (a) Slip-rate uncertainties associated with each fault. Black square, slip rate used in Pace et al. [2006] and revised according to the literature. (b) Mean recurrence times (left y-axis) and aperiodicities (ALFA, right y-axis) assigned to the faults in 2006 (gray bars) and in 2009 (colored bars) according to the error propagation technique described by Peruzza et al. [2010].

\section{SB - Seisogenic Boxes}

The global approach to the treatment of individual sources remains the same with respect to Pace et al. [2006], although some modifications linked to recent studies have been introduced. The modifications have conceptual/theoretical implications and some impact in terms of expected hazard. With the occurrence of the L'Aquila earthquake, on April 6, 2009, we introduced a major change with respect to the 2006 model: the time elapsed since the last event, calculated at August 1, 2009, dropped to zero years for the Paganica source (ID 12 in Figure $1 \mathrm{~b}$ and Table 2), as the $M 6.3$ earthquake that nearly occurred is considered to be its characteristic event. Conversely, the earthquake-fault association and occurrence models assigned to the faults remained the same as in the previous study [Pace et al. 2006: tables 2, 3; reported here in Table 2].

The modifications and implementations that we made for the CSEP project concerned:

a) Revision of geometries and characteristic earthquake associations for the northern-most sources 26-27-28 in Pace et al. [2006] (Città di Castello Basin), which in the light of recent detailed work by Brozzetti et al. [2009], is now considered to be two sources (26-27) with slightly different geometries.

b) Updating of slip rates using recent studies. The slip rates were mainly inferred from detailed topographic profiles across the scarp, assuming that the displacement had accumulated from the last glacial maximum in central Italy from $\sim 18,000$ years ago [Roberts 2006, and references therein], and from paleoseismological trenches [Galli et al. 2008, and references therein]. To determine the error propagation, we evaluated the minimum and maximum slip rates using the values given in the studies, or we assigned an inferred error of $50 \%$ to the faults with unknown uncertainties. For some sources (Figure 5a, ID 8, 14, 20-22), the slip rate revision led to newly defined ranges that did not contain the original slip rates used by Pace et al. [2006].

c) Introduction of formal error propagation for assigning the mean recurrence time $\left(T_{\text {mean }}\right)$ of the characteristic events and aperiodicity [see Peruzza et al. 2010, for methodology]. The updated values are given in Figure $5 \mathrm{~b}$ and Table 2 , and their roles in the earthquake probabilities will be commented on below.

d) Computation of earthquake probabilities with more accurate algorithms (Figure 6). We found and fixed some problems that related to the numerical precision when computing the conditional probabilities on the tail of the BPT function. Numerical precision problems were responsible for earthquake probability underestimates for some sources in the previous 2006 model, namely those characterized by the longest elapsed times (e.g., 2-Gorzano, 3-Gran Sasso).

Points c) and d) (error propagation and correct computation of conditional probabilities) proved to be nontrivial issues; they were the key to the changes in the earthquake probabilities for SBs in central Italy of the LASSCI version 2009.1 (LASSCI2009.1) [Peruzza et al. 2011], which had been prepared for the CSEP validation test before the L'Aquila earthquake, with respect to the original 2006 version. In particular, the Paganica source turned out to be the most probable source (with more than a $30 \%$ of probability of having a characteristic event in the 5 years following 2009), without any change in source geometry or earthquake association (the last event assigned to this fault was in 1461). After the L'Aquila earthquake (LASSCI2009.2) its probability 


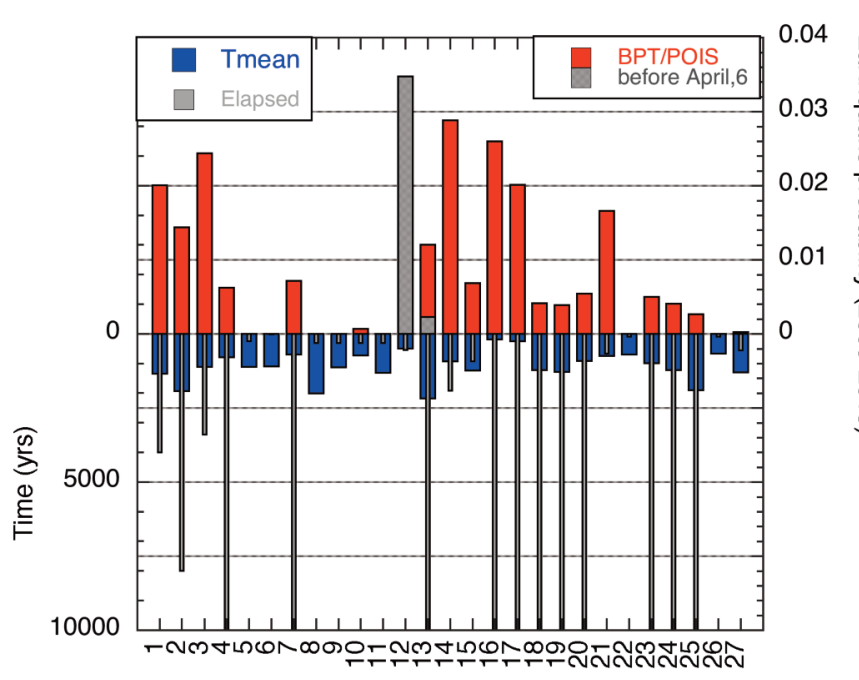

Figure 6. Earthquake probabilities (Y-axis, right) of a $M_{\max }$ event in 5 years for the LASSCI SB sources as computed for the CSEP test. The conditional probability of occurrence in the next 5 years from August 1, 2009, were calculated using the BPT distributions for sources where time-dependency was applied (Table 2, final column), or by exponential distribution (Poisson hypothesis, memoryless) in the other cases. On the left Y-axis, the mean recurrence time and elapsed time are given (elapsed time set to 9999 years if unknown). LASSCI2009.1 (forecast on April 1, 2009) and LASSCI2009.2 (forecast on August 1, 2009) differ in terms of their source 12-Paganica (the elapsed time dropped from 548 to 0 years due to the occurrence of the L'Aquila earthquake) and source 13-Media Valle Aterno (as new paleoseismological data were made available by Falcucci et al. [2009], and the source was not treated as Poissonian any more).

dropped to zero as the elapsed time since the last event dropped from 548 years to 0 . In this second, LASSCI2009.2, release, the nearby SB 13 (Media Valle Aterno; see Table 2) was assigned an increased probability, as the source was treated as Poissonian (no date for a previous earthquake; Figure 6, gray bar) in the 2009.1 release, while the preliminary results of the paleoseismological trenches obtained after the L'Aquila earthquake suggested that this source should be treated with time-dependency (the last event was approximately 3,000 years ago) [Falcucci et al. 2009]. In theory, retrospective testing of forecasts linked to this source layer is not feasible for time-dependent SBs (Table 2, last column), as the conditional probability changed with the starting time of the forecast period; in practice, it should be used carefully for retrospective testing only if the time elapsed is not significantly different from the time used here, or if the most recently activated sources are excluded (e.g., the Paganica fault).

The seismicity distributions assigned to each SB, which were modeled as previously described in Section 2, were finally partitioned between the CSEP grid nodes intersecting the source polygon. The partitioning was carried out by considering the percentage of the area covered by each CSEP cell, with respect the total area of the SB (Table 1).

\section{Results}

In Figure 7, the expected seismicity rates in central Italy are summarized, as calculated for the 5 years starting from August 1, 2009, for five example magnitude bins. The magnitude range from 5.0 to 7.0 highlights the contributions of each of the three layers of the LASSCI to the total computation of the expected seismicity rates. All of the results in terms of seismicity rates shown in the maps of Figure 7 refer to an area of $0.1^{\circ} \times 0.1^{\circ}$ (latitude $\times$ longitude), centered on the CSEP testing area nodes.

Figure 7 a shows the magnitude $M=5.0$ data, where there is a high spatial variability of the expected seismicity due to the contribution of the background seismicity. Although the 1997-1998 Umbria-Marche seismic sequence was not represented in the instrumental catalog that spans from 1981 to 1996, simply because it had not yet occurred, the results show significant rates in the Colfiorito area and in an E-W elongated strip that reached the coast south of Ancona. Seismicity rates as high as those for Umbria-Marche were expected in the area between Mt. Gorzano and L'Aquila, and south of Barrea. Also, the area around the town of Chieti that was affected by only a few of the events in the 1981-1996 period, had a local seismicity rate maximum, with expected values between $10^{-4}$ and $10^{-3}$ events of $M=5.0$ in 5 years. The areas with the lowest seismicity rates are concentrated west of the volcanic district of Lake Bolsena (northwest of Viterbo) and around the easternmost city of Pescara along the Adriatic coast. A comparison of these data with those obtained with the INGV catalog from April 2005, which was more limited in time, but much more complete in magnitudes detected, is under analysis at present and will be the subject of future investigations.

Figure $7 \mathrm{~b}$ shows the expected seismicity rates for $M=5.5$, whereby the contributions of the individual SBs and SPs become clear. The BK layer was absent due to the upper boundary of $M=5.3$ that was chosen for that layer. Some spatial clusters of high rates were located in the SBs where a G-R or hybrid model was assigned; in that magnitude bin, the Gaussian distribution used to represent the «characteristic earthquake» model was nearly always already truncated. In agreement with historical observations, SP-C and SP-D gave higher values than SP-A. However, the rates were homogeneously distributed between the SPs, as no earthquake-fault association was given.

For magnitude bins in the range $M=6.0-7.0$, there was little spatial variability in the earthquake rates inside SP-B, as each SB had its own occurrence model that varied in terms of the functional shape (logarithmic G-R behavior, Gaussian $\mathrm{CH}$, or both $\mathrm{HY}$; see Table 2), time dependency, elapsed time and maximum assigned magnitude. For $M=6.0$ (Figure 7c), the contribution of a few sources $(4,7,14,18$ and 24) became prominent, whereas the remaining sources have rates similar to SP-C and SP-D.

A comparison between the expected rates for $M=6.5$ for the analysis of April 1, 2009 (LASSCI2009.1; computed before the L'Aquila earthquake; Figure 7e) and those for the 

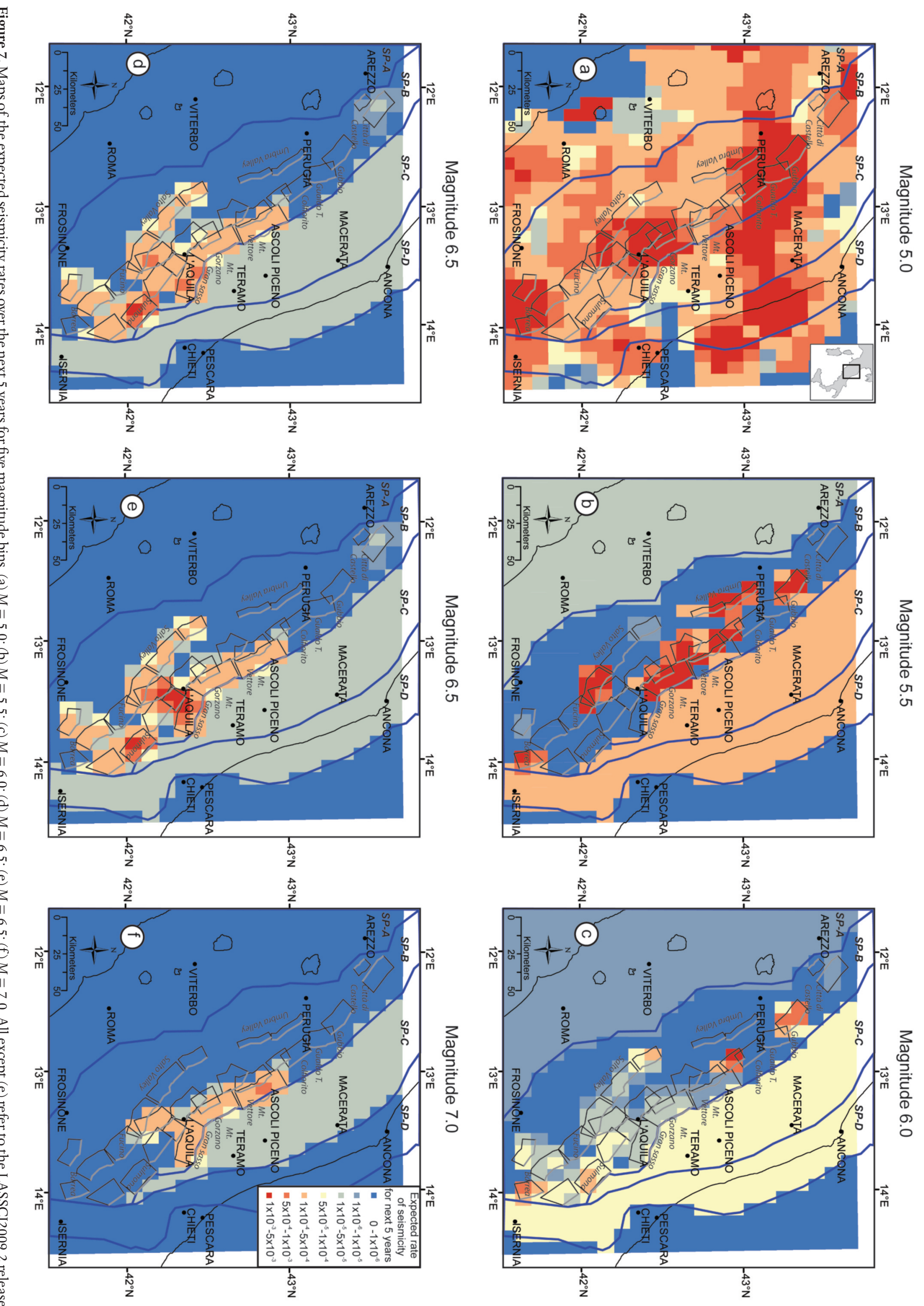


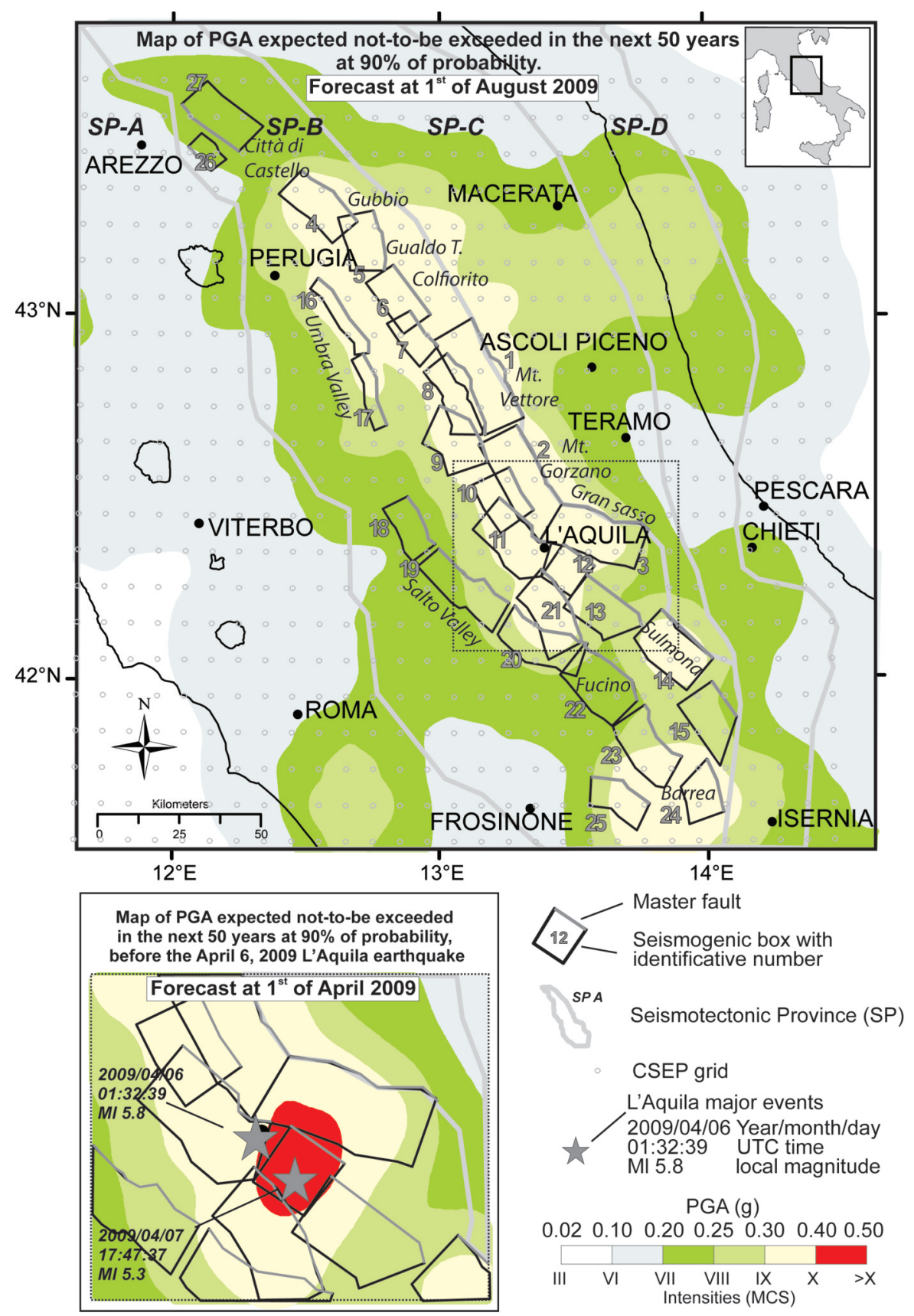

Figure 8. Map of the peak ground acceleration expected not to be exceeded in 50 years at a $90 \%$ probability level in central Italy, using the time-dependent LASSCI2009.2, updated for the CSEP validation test. The forecast was for August 1, 2009. The code SEISRISKIII by Bender and Perkins [1987] and the Ambraseys et al. [1996] attenuation relationship were used. The enlargement shows the forecast on April 1, 2009 (release LASSCI2009.1) in the L'Aquila region. The stars show the locations of the major events that were reported. Legend: a rough correlation between peak ground acceleration values and macroseismic intensities (MCS) derived from Italian literature [Margottini et al. 1992, Decanini et al. 1995].

analysis of August 1, 2009 (after the event of April 6, 2009; Figure $7 \mathrm{~d}$ ) was of particular interest. In Figure $7 \mathrm{e}$, the earthquake rates showed two local maxima around sources 12 (Paganica) and 14 (Sulmona). After the L'Aquila earthquake (Figure $7 \mathrm{~d}$ ), a seismicity rate maximum remained in source 14 and the expected seismicity decreased for source 12. High seismicity rates still characterized many other sources in the central Apennines. Finally, for $M=7.0$, the highest rates were located around the largest sources: the Mt. Vettore-Gran Sasso alignment (sources 1 to 3), and the Campo Felice-Ovindoli SB (source 21) in the central part of the study area.

\section{Discussion}

According to the CSEP forecasting rules and the deadlines set up for the Italian testing region of the CSEP project, we updated and improved our regional model published in 2006. We calculated the expected seismicity rates in central Italy with a release of the model (LASSCI2009.1) that was ready to be submitted for the initial deadline of April 1, 2009 [download available in Peruzza et al. 2011]. The shift of the submission deadline and the occurrence of the L'Aquila event on April 6, 2009, led to a second release (LASSCI2009.2) that underwent testing starting on August 1, 2009. The experiment is expected to 
end in 2014 and 2019 (for the 5-year and 10-year forecasts, respectively) and will evaluate the credibility of the LASSCI.

At present, the LASSCI2009.1 release allows an immediate retrospective test of our model. The probabilities of a maximum magnitude earthquake in an individual SB are shown in Figure 6. These values were derived from a parameterization of the maximum earthquake size and the recurrence times constrained by the fault characteristics, and they were not exclusively limited to direct observations of earthquakes. A simple renewal process was applied to some SBs, abandoning the stationary assumptions that have been commonly used in earthquake ratings. This mimics elastic rebound theory, but neglects fault interactions. On April 1, 2009, the highest conditional probability of having a characteristic event (more than $30 \%$ in the next 5 years) was assigned to the Paganica-12 SB, where the April 6, 2009, event occurred [Walters et al. 2009]. In the LASSCI2009.2 release, this had decreased to zero, due to the change in the elapsed time from 548 to 0 years. According to some studies, the Paganica source was one of the individual sources recognized in central Italy before the earthquake; however, some other sources had significant probabilities of having a $M>6$ earthquake, as they represented long-lasting silent faults. Of note, in our model the occurrence of the L'Aquila earthquake did not significantly reduce the aggregate probability of having at least one large earthquake $(M>6)$ in this area [Peruzza et al. 2011]. Homogeneously distributed earthquake rates were modeled in nearby SPs, as no better geometrical constraint to individual sources is feasible at present. For low magnitudes $(M=5.0)$, the LASSCI predicted rates higher than $10^{-4}$ earthquakes in 5 years in cells of size $0.1^{\circ} \times 0.1^{\circ}$, in nearly all of the cells in the study area. However, the seismicity is poorly constrained along the coasts. In the framework of a renewal model that did not account for fault interactions, the 14-Sulmona source is now the most probable active fault that has been recognized in the extensional SP along the central Apennines, where some recent studies have enhanced the role of static stress changes for accelerating the seismic cycle on the nearby 2-Gorzano fault [Walters et al. 2009: Campotosto fault]. Since summer 2009, a temporary seismometric network managed by our institutions has been recording the microseismic activity in the southern part of the middle Aterno Valley (SB 13) around the Sulmona basin [de Nardis et al. 2010].

Even though the earthquake rates showed large spatial variabilities between the magnitude bins (see Figure 7), these were not reflected in the seismic hazard map. In Figure 8, the time-dependent seismic hazard map given in terms of peak ground acceleration is expected not to be exceeded at $90 \%$ probability in the next 50 years (starting from August 1, 2009), and it is useful for identifying the most hazardous areas in central Italy where, according to our model, prompt seismic risk reduction strategies are needed. The expected peak ground acceleration values near L'Aquila before the 2009 seismic sequence (LASSCI2009.1) are shown in the expanded panel of Figure 8, and they were consistent with the values recorded by the national accelerometric network (Rete Accelerometrica Nazione-RAN) [Ameri et al. 2009, Gorini et al. 2010] and with the macroseismic intensities that were experienced [Galli and Camassi 2009; converted into peak ground acceleration values by common correlation relationships; e.g., Margottini et al. 1992, Decanini et al. 1995]. This is because in this particular probabilistic representation ( $90 \%$ chance of not being exceeded in 50 years, corresponding to 475 years return time), the fictitious recurrence time $T_{\text {fictitious }}=$ 135 years assigned to a characteristic event on the Paganica source corresponded to a deterministic scenario inside this source $\left(p \sim 97 \%=1-\mathrm{e}^{(-475 / 135)}\right)$ [see also Peruzza et al. 2011].

Nevertheless, as a model cannot be validated by one earthquake, we trust that the CSEP project will help in answering open questions, such as the superiority of stationary versus time-dependent assumptions, the role of fault interactions, the applicability of the characteristic earthquake model versus G-R behavior, and the reliability of the fault characteristics in estimating earthquake parameters and their uncertainties.

In Italy, we hope sufficient energies and funds will be invested in a wide range of seismic retrofitting projects, to avoid the casualties we suffered in 2009 .

Acknowledgements. This study was supported by DPC-INGV funds for Project S2: Development of a dynamical model for seismic hazard assessment at national scale (L.P. and B.P.) and Fondi Ateneo ex $60 \%$ (B.P.). We thank the two anonymous reviewers for their extremely accurate check of the manuscript and long lists of suggestions. We are also grateful to the Guest Editor, Danjiel Schorlemmer, as his recommendations and encouragement were essential.

\section{References}

Ambraseys, N.N., K.A. Simpson and J.J. Bommer (1996). Prediction of horizontal response spectra in Europe, Earthquake Engineering and Structural Dynamics, 25, 371-400.

Ameri, G., P. Augliera, D. Bindi, E. D'Alema, C. Ladina, S. Lovati, L. Luzi, S. Marzorati, M. Massa, F. Pacor and R. Puglia (2009). Strong-motion parameters of the $M_{w}=6.3$ Abruzzo (central Italy) earthquake, Open File Report; http:/ / www.mi.ingv.it/docs/report_RAN_20090406.pdf Barchi, M., F. Galadini, G. Lavecchia, P. Messina, A.M. Michetti, L. Peruzza, A. Pizzi, E. Tondi and E. Vittori (eds.) (2000). Sintesi delle conoscenze sulle faglie attive in Italia Centrale: parametrizzazione ai fini della caratterizzazione della pericolosità sismica, Roma, CNR-Gruppo Nazionale per la Difesa dai Terremoti, $62 \mathrm{pp}$.

Bender, B. and D.M. Perkins (1987). SEISRISK III; a computer program for seismic hazard estimation, U. S. Geological Survey, Reston, VA, United States, 48 pp.

Boncio, P., G. Lavecchia and B. Pace (2004). Defining a model 
of 3D seismogenic sources for seismic hazard assessment applications: The case of central Apennines (Italy), Journal of Seismology, 8, 407-425.

Brozzetti, F., P. Boncio, G. Lavecchia and B. Pace (2009). Present activity and seismogenic potential of a low-angle normal fault system in central Italy (Città di CastelloSansepolcro area): constraints from surface geology, seismic reflection data and seismicity, Tectonophysics, 463, 31-46.

Chiarabba, C. et al. (2009). The 2009 L'Aquila (central Italy) $M_{\mathrm{w}} 6.3$ earthquake: Main shock and aftershocks, Geophysical Research Letters, 36, L18308; doi: 10.1029/ 2009 GL039627.

CPTI Working Group (2004). Catalogo Parametrico dei Terremoti Italiani, versione 2004 (CPTI04), INGV, Bologna; http: / / emidius.mi.ingv.it/CPTI04/.

CSTI Working Group (2001). Catalogo Strumentale dei Terremoti Italiani dal 1981 al 1996, versione 1.0, INGVGNDT, CD-Rom; http: / ibogfs.df.unibo.it/user2/paolo/ www/gndt/PE98/PE98.html.

Decanini, L., C. Gavarini and F. Mollatoli (1995). Proposta di definizione delle relazioni tra intensità macrosismica e parametri del moto del suolo, $7^{\circ}$ Convegno Nazionale «L'Ingegneria Sismica in Italia» (Siena, September 25-28, 1995), Proceedings, 1, 63-72.

De Nardis, R., M. Garbin, G. Lavecchia, B. Pace, L. Peruzza, E. Priolo, M. Romanelli, M.A. Romano, F. Visini and A. Vuan (2010). A temporary seismic monitoring of the Sulmona area (Abruzzo, Italy) for seismotectonic purposes, Bollettino di Geofisica Teorica ed Applicata, submitted.

Di Luccio, F., A. Amato, R.M. Azzara, A. Basili, A. Delladio, M. Di Bona, A. Gorini, F.P. Lucente, S. Marcucci, L. Margheriti, G. Milana, F. Ponziani, G. Selvaggi and E. Zambonelli (1997). La sequenza sismica del maggio 1997 a Massa Martana (PG), $16^{\circ}$ Convegno Nazionale GNGTS, (Roma, 11-13 novembre 1997), Riassunti delle comunicazioni, 65.

Falcucci, E., S. Gori, M. Moro, F. Galadini, S. Marzorati, C. Ladina, D. Piccaredda and P. Fredi (2009). Evidenze di fagliazione normale tardo-olocenica nel settore compreso tra la Conca Subequana e la Media Valle dell'Aterno, a sud dell'area epicentrale del terremoto di L'Aquila del 6 Aprile 2009: implicazioni sismotettoniche, 28th Annual Meeting GNGTS (Trieste, November 16-19, 2009), Extended abstract, 161-163; available at http: / / www2.ogs. trieste.it/gngts/.

Frepoli, A. and A. Amato (1997). Contemporaneous extension and compression in the Northern Apennines from earthquake fault-plane solutions, Geophysical Journal International, 129, 368-388.

Galadini, F. and P. Galli (2000). Active tectonics in the Central Apennines (Italy) - Input data for Seismic Hazard Assessment, Natural Hazards, 22, 225-270.

Galadini, F., C. Meletti and E. Vittori (2000). Stato delle cono- scenze sulle faglie attive in Italia: elementi geologici di superficie, In: Galadini, F., C. Meletti and A. Rebez (eds.), Le ricerche del GNDT nel campo della pericolosità sismica (1996-1999), CNR-Gruppo Nazionale per la Difesa dai Terremoti, Roma, 107-136.

Galli, P., F. Galadini and D. Pantosti (2008). Twenty years of paleoseismology in Italy, Earth-Science Reviews, 88, 89-117.

Galli, P. and R. Camassi (eds.) (2009). Rapporto sugli effetti del terremoto aquilano del 6 aprile 2009, INGVProtezione Civile Nazionale; http: / /www.mi.ingv.it/eq/ 090406/ quest.html.

Gasparini, C., G. Iannaccone and R. Scarpa (1985). Fault-plane solutions and seismicity of the Italian Peninsula, Tectonophysics, 117, 59-78.

Gorini, A., M. Nicoletti, P. Marsan, R. Bianconi, R. De Nardis, L. Filippi, S. Marcucci, F. Palma and E. Zambonelli (2010). The Italian strong motion network, Bulletin of Earthquake Engineering, 8 (5), 1075-1090.

Jordan, H.J., E.H. Field and P. Somerville (2006). USC-SCEC / CEA technical report \#1, Southern California Earthquake Center, Los Angeles, CA.

Knopoff, L. (2000). The magnitude distribution of declustered earthquakes in Southern California, PNAS, 97 (22), 1188011884.

Margottini, C, D. Molin and L. Serva (1992). Intensity versus ground motion: a new approach using Italian data, Eng Geol, 33, 45-58.

Matthews, M.V., W.L. Ellsworth and P.A. Reasenberg (2002). A Brownian model for recurrent earthquakes, Bulletin of the Seismological Society of America, 92 (6), 2233-2250.

MPS Working Group (2004). Redazione della mappa di pericolosità sismica prevista dall'Ordinanza PCM 3274 del 20 marzo 2003, Rapporto conclusivo per il Dipartimento della Protezione Civile, INGV, Milano-Roma, April 2004 (MPS04), 65 pp. + 5 appendices; http://zonesismiche.mi.ingv.it.

Pace, B., L. Peruzza, G. Lavecchia and P. Boncio (2006). Layered Seismogenic Source Model and Probabilistic Seismic-Hazard Analyses in Central Italy, Bulletin of the Seismological Society of America, 96 (1), 107-132.

Peruzza, L., B. Pace, G. Lavecchia and P. Boncio (2007). Reply to «Comment on Layered Seismogenic Source Model and Probabilistic Seismic-Hazard Analyses in Central Italy by Pace, B., Peruzza, L., Lavecchia, G. and Boncio, P.» by W. Marzocchi, Bulletin of the Seismological Society of America, 97 (5), 1766-1768.

Peruzza, L., B. Pace and F. Cavallini (2010). Error propagation in time-dependent probability of occurrence for characteristic earthquakes in Italy, Journal of Seismology, 14 (1), 119-141; doi: 10.1007/s10950-008-9131-1.

Peruzza, L., B. Pace and F. Visini (2011). Fault-based earthquake rupture forecast in Central Italy: lessons learned with the L'Aquila $M_{\mathrm{w}} 6.3$ event, Bulletin of the Seismological Society of America, 101 (1), in press. 
Riguzzi, F., A. Tertulliani and C. Gasparini (1989). Study of the seismic sequence of Porto San Giorgio (Marche), 3 July 1987, Il Nuovo Cimento, 12 (4), 453-466; doi: $10.1007 / \mathrm{BF} 02525078$.

Roberts, G.P. (2006). Multi-seismic cycle velocity and strain fields for an active normal fault system, central Italy, Earth and Planetary Science Letters, 251, 44-51.

Santini, S. (2003). A note on Northern Marche seismicity: new focal mechanisms and seismological evidence, Annals of Geophysics, 46 (4), 725-731.

Schorlemmer, D., T.H. Jordan, J.D. Zechar, P.J. Maechling, M. Gerstenberger and S. Wiemer (2006). Collaboratory for the Study of Earthquake Predictability (CSEP), American Geophysical Union, Fall Meeting 2006, abstract \#S12A-01; http://www.cseptesting.org/documents/talks. Schorlemmer, D., D.D. Jackson, J.D. Zechar and T.H. Jordan (2009). Collaboratory for the Study of Earthquake Predictability: Design of Prediction Experiments, American Geophysical Union, Fall Meeting 2009, abstract \#NH13A-1133.

Walters, R.J., J.R. Elliott, N. D'Agostino, P.C. England, I. Hunstad, J.A. Jackson, B. Parsons, R.J. Phillips and G. Roberts (2009). The 2009 L'Aquila earthquake (central Italy): A source mechanism and implications for seismic hazard, Geophysical Research Letters, 36; doi: 10.1029/2009GL039337

WGCEP (Working Group on California Earthquake Probabilities) (2008). The Uniform California Earthquake Rupture Forecast, version 2 (UCERF 2): U.S. Geological Survey Open-File Report 2007-1437 and California Geological Survey Special Report 203; http:/ / pubs.usgs. gov/of/2007/1091/.

${ }^{\star}$ Corresponding author: Bruno Pace, GEOSISLAB - Università degli Studi "G. D'Annunzio", Chieti Scalo, Italy; email: b.pace@unich.it

(C) 2010 by the Istituto Nazionale di Geofisica e Vulcanologia. All rights reserved. 